Journal of Zhejiang University-SCIENCE A (Applied Physics \& Engineering)

ISSN 1673-565X (Print); ISSN 1862-1775 (Online)

www.zju.edu.cn/jzus; www.springerlink.com

E-mail: jzus@zju.edu.cn

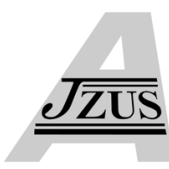

Editorial:

\title{
Key research on computer aided tolerancing*
}

Yan-long $\mathrm{CAO}^{\dagger 1}$, Luc MATHIEU $^{2}$, Jane JIANG ${ }^{3}$

(Guest Editors-in-Chief)

$\left({ }^{1}\right.$ The State Key Laboratory of Fluid Power Transmission and Control, School of Mechanical Engineering, Zhejiang University, Hangzhou 310027, China)

$\left({ }^{2} L U R P A\right.$, ENS Cachan, 61 Avenue du Président Wilson, Cachan Cedex, 94235, France)

$\left({ }^{3}\right.$ EPSRC Centre for Innovative Manufacturing in Advanced Metrology, University of Huddersfield, Huddersfield, HD1 3DH, UK)

†E-mail: sdcaoyl@zju.edu.cn

doi:10.1631/jzus.A1500093

Computer aided tolerancing (CAT) covers a wide range of subjects including specification and standardization, tolerancing in design/manufacturing process/product life management, verification and metrology, and functional tolerancing.

Dimensioning and tolerancing standards originated about 77 years ago in the form of various national and company standards that governed engineering drafting and documentation practices. These standards have evolved and their rapid development has brought about many significant changes to tolerancing in design and manufacturing. The release of ISO 14405-1:2010 (ISO, 2010) has introduced a rich new set of size specification modifiers, which includes two-point and spherical local sizes least squares, maximum inscribed and minimum circumscribed associations, and calculated diameters. Morse et al. (2012) present "size" as a fundamental engineering notion from several viewpoints, trace its evolution in engineering drawings, and discuss the implications of the use of size modifiers.

\footnotetext{
* Project supported by the Science Fund for Creative Research Groups of National Natural Science Foundation of China (No. 51221004), the National Natural Science Foundation of China (No. 51275464), and the National Basic Research Program (973) of China (No. 2011CB706505) (1D ORCID: Yan-long CAO, https://orcid.org/0000-0003-0383-6586 (c) Zhejiang University and Springer-Verlag Berlin Heidelberg 2015
}

Many researchers have devoted their efforts to tolerancing modeling. Davidson et al. (2002) develop a tolerance maps (T-Maps) (Patent No. 6963824) model that is a hypothetical Euclidean volume of points, the shape, size, and internal subsets of which represent all possible variations in size, position, form, and orientation of a target feature. Jiang et al. (2014) describe the use of T-Maps and manufacturing maps (M-maps) to establish analytical relationships among all relevant design and machining tolerances for the transfer of cylindrical data. Clément et al. (1991) introduce a small displacement torsor (SDT) model using six small displacements to represent the position and orientation of an ideal surface in relation to another ideal surface in a kinematic way. Giordano et al. (2007) apply deviation domains to axi-symmetric cases and thus reduce the space to three dimensions at the maximum instead of six in the general case. Desrochers et al. (2003) put forward a unified Jacobian-Torsor model which combines the advantages of the torsor model and the Jacobian matrix. Ghie et al. (2010) describe how the same set of interval-based deterministic equations can be used in a statistical context. Anwer et al. (2013) investigate the fundamentals of the skin model at a conceptual, geometric, and computational level and present representation and simulation issues for product design. In another paper (Anwer et al., 2014), they investigate the concept of skin model shapes that has been developed to address digital representation of "non-ideal" parts and extended to mechanical assemblies. This concept is an interesting solution for tolerance analysis in the same way of finite element analysis, inspection analysis, and other analysis in mechanical engineering based on discrete geometry.

Tolerance analysis, as an essential element in industry, carries considerable weight in concurrent engineering, and represents the best way to solve 
problems in order to ensure higher quality and lower costs. Dantan et al. (2013) deal with tolerance analysis formulation, more particularly, with the uncertainty that must be taken into account in the foundation of this formulation. Walter et al. (2013) consider an extension of the existing "integrated tolerance analysis of systems in motion" approach. Mansuy et al. (2011) present an original method that enables us to develop specifications based on standards and calculate tolerances for the case of serial assembly (stacking) without clearances. This method is based on the use of influence coefficients to obtain the relationship between the functional tolerance and tolerances associated with the geometry of the mechanism's interface surfaces. Qureshi et al. (2012) propose a statistical tolerance analysis approach for an over-constrained mechanism based on optimization and Monte Carlo simulation. Bruyère et al. (2007) propose an approach for analyzing tolerances that includes a vectorial dimensioning and tolerancing model. This allows gear conventional tolerancing practice and geometric tolerancing practice, a digital simulation based on tooth contact analysis and Monte Carlo simulation. Gao et al. (1998) introduce a direct linearization method (DLM) based on the first order Taylor series expansion of vector-loop-based assembly models which use vectors to represent either component or assembly dimensions. Worst-case tolerance analysis gives results that are overly pessimistic, resulting in the increasing cost of products. Statistical tolerance analysis takes the statistical behavior of manufacturing variations into consideration. Statistical tolerancing is a more practical and economical way of looking at tolerances and works on setting the tolerances so as to ensure a desired yield. By permitting a small fraction of assemblies to not assemble or function as required, an increase in tolerance for individual dimension may be obtained, and in turn manufacturing costs may be reduced significantly (Nigam and Turner, 1995). Statistical tolerancing methods or approaches include the root-sumsquares (RSS) method (Bender, 1968), system moments (Evans, 1975a; 1975b), quadrature (Evans, 1971; 1972), the reliability index (Parkinson, 1982; Lee and Woo, 1990), the Taguchi method (Taguchi, 1978; D’Errico and Zaino, 1988), and Monte Carlo simulations (Bruyère et al., 2007; Dantan and Qureshi, 2009; Wu et al., 2009; Qureshi et al., 2012).

Quality control, verification, and metrology have been the focus of manufacturing enterprises. In the scope of quality control, accurate evaluation of measurement uncertainties is a real challenge in improving the use of coordinate measuring machines (CMM). Ballu and Mathieu (1996) propose a univocal expression of functional and geometrical tolerances for design, manufacturing, and inspection. This language has been retained by ISO for the future geometrical product specification (GPS) standards ISO 17450-1:2005 (ISO, 2005). Sprauel et al. (2003) describe a new method, based on a statistical approach to the problem, to deduce instantaneous measurement uncertainties directly from the set of acquired coordinates. Krämer and Weckenmann (2010) describe the fusion of multi-energy stacks to measure objects of high aspect ratios and parts consisting of different absorbing materials. Savio et al. (2002) compare two different experimental methods for establishing the traceability of freeform measurements on coordinate measuring machines: (i) uncertainty assessment using nodular freeform gauges, and (ii) uncertainty assessment using uncalibrated objects. They demonstrate the feasibility of the two approaches for freeform geometries through the calibration of a turbine blade. Moroni and Petrò (2014) propose a model for evaluation of the overall inspection cost based on uncertainty evaluation, and propose two methodologies for evaluating the uncertainty.

Functional tolerancing has now been well accepted by industry and become a major field of interest for academia. Mcadams (2003) develops tolerance design principles through a careful study of the literature, observation of commonly recurring tolerance solutions, and design strategies implied by the existing tolerance design literature. These principles provide a focus for developing new methodologies that will have high impact on engineering practice. Islam (2004) describes the development of a prototype software package for solving functional dimensioning and tolerancing (FD\&T) problems in a concurrent engineering environment. Hunter et al. (2008) use a functional tolerance model providing a complete framework to define the geometric 
dimensioning and tolerancing and its relationship with the part geometry and the inspection process in order to establish a connection between a computer aided design and computer aided inspection system. Yang et al. (2013) make a brief comparison of existing 3D functional tolerance analysis models, and propose a statistical tolerancing approach based on variation of point-set. Cao et al. (2013) propose a scheme for functional specification in accordance with the new generation of geometrical product specifications. To study the functional tolerance specification methods consistent with the new generation of GPS, Yang et al. (2010) study the class of positioning joints of part assembling and the principle of determining its priority on the basis of definition of invariance class of GPS. In this paper, a new functional tolerancing method from geometrical functional requirement to geometrical specification is presented. Etienne et al. (2008) propose an approach in order to allocate the functional tolerances that provide the best ratio between functional performances and manufacturing cost.

The CIRP (International Academy for Production Engineering) Conference on Computer Aided Tolerancing (CAT) is initiated and supported scientifically every two years by two CIRP Scientific Technical Committees (STCs): Design (STC Dn) and Precision Metrology (STC P) to address the emerging problems of CAT, which has a prominent role at the interface between product design and manufacturing. The 13th CIRP CAT Conference held at Zhejiang University, Hangzhou, China during May 11-14, 2014 was the successor to the twelve earlier conferences held in Israel (1989), the USA (1991; 2003; 2005), France (1993; 2001; 2009), Japan (1995), Canada (1997), the Netherlands (1999), Germany (2007), and the UK (2012).

Note that the evolution of CAT involves far more than the results or research mentioned above and benefits from the efforts of people from many different cultures and backgrounds. We are pleased to publish in this special part issue a selection of six papers that were presented at the conference in Hangzhou. These papers cover a wide spectrum of current international research in CAT.

For purposes of automating the assignment of tolerances during design, a math model, called the
T-Map, has been produced for most of the tolerance classes that are used by designers. Like deviation domains, T-Map is a hypothetical Euclidean volume which represents all possible deviations in size, orientation and position of a feature. The paper titled "Tolerance-Maps for line-profiles constructed from Boolean intersection of T-Map primitives for arc-segments" proposes a method to produce a T-Map for the complete line profile of any shape. The method firstly decomposes a profile into segments, then creates a solid-model T-Map primitive for each, and finally combines these by Boolean intersection to generate a T-Map of the profile.

Tolerance analysis is attracting increasing attention from different disciplines. In the paper titled "An iterative statistical tolerance analysis procedure to deal with linearized behavior models" analyzes the impact of a linearization strategy on the probability of failure estimation, and proposes an iterative procedure for the assembly requirement in order to provide accurate results without driving the entire Monte Carlo simulation. In the paper titled "A statistical method to identify main contributing tolerances in assemblability studies based on convex hull techniques" the authors propose a method to adopt a global sensitivity analysis based on deviation domains to obtain recommendations for optimizing tolerance values and apply the method to assemblability studies.

Tolerances influence the quality of manufacturing surfaces. The paper titled "Effects of geometric and spindle errors on the quality of end turning surface" develops an integrated volumetric error model applied to a lathe by the method of rigid body dynamics and homogeneous coordinate transformation. After the simulated surface is generated by a linear mapping of the volumetric errors on the ideal turning surface, the effect of volumetric errors on the precision and quality of the turning surface is analyzed. Since such errors affect quality, in the paper titled "An adaptive design method for understanding tolerance in the precision stamping process", the authors propose an adaptable control method for tolerance. Fluctuations of tolerance are analyzed which are caused by precision stamping elements in the manufacturing process firstly. Then, the condition-driven adaptive control system is constructed based on the 
monitoring system and hydraulic control system. Thirdly, executive parameters (such as velocity, pressure, gaps, etc.) are calculated in the control module. Then stamping tolerances of precision parts are ensured accuracy in precision stamping process.

Linear convolution and morphological (nonlinear) operations are two kinds of operations that have wide applications in the field of surface measurement. The paper titled "A theoretical insight into morphological operations in surface measurement by introducing the slope transform" introduces a counterpart transform, called the slope transform, which provides the analytical ability for morphological operations and offers a deeper understanding of morphological operations in surface measurement. By investigating the slope and curvature change, the slope transform can offer a deeper understanding of morphological operations in surface measurement.

CIRP CAT 2014 was sponsored by the International Academy for Production Engineering, the School of Mechanical Engineering, Zhejiang University, and co-sponsored by the National Natural Science Foundation of China (NSFC). On behalf of the organizing committee, we appreciate all the support received from the keynote speakers and presenters. This support was indispensable for us to deliver a successful conference.

\section{References}

Anwer, N., Ballu, A., Mathieu, L., 2013. The skin model, a comprehensive geometric model for engineering design. CIRP Annals-Manufacturing Technology, 62(1):143-146. [doi:10.1016/j.cirp.2013.03.078]

Anwer, N., Schleich, B., Mathieu, L., et al., 2014. From solid modelling to skin model shapes: Shifting paradigms in computer-aided tolerancing. CIRP AnnalsManufacturing Technology.

Ballu, A., Mathieu, L., 1996. Univocal expression of functional and geometrical tolerances for design, manufacturing and inspection. Computer-aided Tolerancing, Springer, p.31-46.

Bender, A., 1968. Statistical Tolerancing as it Relates to Quality Control and the Designer (6 times 2.5=9). SAE Technical Paper.

Bruyère, J., Dantan, J.Y., Bigot, R., et al., 2007. Statistical tolerance analysis of bevel gear by tooth contact analysis and Monte Carlo simulation. Mechanism and Machine Theory, 42(10):1326-1351. [doi:10.1016/j. mechmachtheory.2006.11.003]

Cao, Y.L., Zhang, H., Li, B., et al., 2013. Study on functional specification scheme on interface based on positioning features. Proceedings of the Institution of Mechanical Engineers, Part B: Journal of Engineering Manufacture, 227(5):745-753. [doi:10.1177/0954405413479112]

Clément, A., Desrochers, A., Rivière, A., 1991. Theory and practice of 3-D tolerancing for assembly. CIRP International Working Seminar on Computer-Aided Tolerancing, Penn State University, p.25-55.

D’Errico, J.R., Zaino, N.A., 1988. Statistical tolerancing using a modification of Taguchi's method. Technometrics, 30(4):397-405. [doi:10.1080/00401706.1988.10488434]

Dantan, J.Y., Qureshi, A.J., 2009. Worst-case and statistical tolerance analysis based on quantified constraint satisfaction problems and Monte Carlo simulation. Computer-Aided Design, 41(1):1-12. [doi:10.1016/j.cad. 2008.11.003]

Dantan, J.Y., Gayton, N., Qureshi, A.J., et al., 2013. Tolerance analysis approach based on the classification of uncertainty (aleatory/epistemic). Procedia CIRP, 10:287293. [doi:10.1016/j.procir.2013.08.044]

Davidson, J., Mujezinovic, A., Shah, J., 2002. A new mathematical model for geometric tolerances as applied to round faces. Journal of Mechanical Design, 124(4): 609-622. [doi:10.1115/1.1497362]

Desrochers, A., Ghie, W., Laperrière, L., 2003. Application of a unified Jacobian-Torsor model for tolerance analysis. Journal of Computing and Information Science in Engineering, 3(1):2-14. [doi:10.1115/1.1573235]

Etienne, A., Dantan, J.Y., Qureshi, J., et al., 2008. Variation management by functional tolerance allocation and manufacturing process selection. International Journal on Interactive Design and Manufacturing (IJIDeM), 2(4):207-218. [doi:10.1007/s12008-008-0055-3]

Evans, D.H., 1971. An application of numerical integration techniques to statistical tolerancing, II-A note on the error. Technometrics, 13(2):315-324. [doi:10.1080/ 00401706.1971.10488786]

Evans, D.H., 1972. An application of numerical integration techniques to statistical tolerancing, III-general distributions. Technometrics, 14(1):23-35. [doi:10.2307/ 1266915]

Evans, D.H., 1975a. Statistical tolerancing-The state of the art. III-Shifts and drifts. Journal of Quality Technology, 7:72-76.

Evans, D.H., 1975b. Statistical tolerancing: The state of the art. II-Methods for estimating moments. Journal of Quality Technology, 7:1-12.

Gao, J., Chase, K.W., Magleby, S.P., 1998. Generalized 3-D tolerance analysis of mechanical assemblies with small kinematic adjustments. IIE Transactions, 30(4):367-377. [doi:10.1023/A:1007451225222]

Ghie, W., Laperrière, L., Desrochers, A., 2010. Statistical tolerance analysis using the unified Jacobian-Torsor model. International Journal of Production Research, 48(15):4609-4630. [doi:10.1080/00207540902824982]

Giordano, M., Samper, S., Petit, J.P., 2007. Tolerance analysis and synthesis by means of deviation domains, axi-symmetric cases. Models for Computer Aided 
Tolerancing in Design and Manufacturing, Springer, p.85-94. [doi:10.1007/1-4020-5438-6_10]

Hunter, R., Guzman, M., Möller, J., et al., 2008. A functional tolerance model: an approach to automate the inspection process. Journal of Achievements in Materials and Manufacturing Engineering, 31(2):662-670.

Islam, M., 2004. Functional dimensioning and tolerancing software for concurrent engineering applications. Computers in Industry, 54(2):169-190. [doi:10.1016/j. compind.2003.09.006]

ISO (International Organization for Standardization), 2005. Geometrical Product Specifications (GPS)-General Concepts-Part 1: Model for Geometrical Specification and Verification, ISO 17450-1:2005. ISO.

ISO (International Organization for Standardization), 2010. Geometrical Product Specifications (GPS)-Dimensional Tolerancing-Part 1: Linear Sizes, ISO 14405-1:2010. ISO, Geneva.

Jiang, K., Davidson, J.K., Liu, J., et al., 2014. Using tolerance maps to validate machining tolerances for transfer of cylindrical datum in manufacturing process. The International Journal of Advanced Manufacturing Technology, 73(1-4):465-478. [doi:10.1007/s00170-0145792-9]

Krämer, P., Weckenmann, A., 2010. Multi-energy image stack fusion in computed tomography. Measurement Science and Technology, 21(4):045105. [doi:10.1088/0957-0233/ 21/4/045105]

Lee, W.J., Woo, T., 1990. Tolerances: their analysis and synthesis. Journal of Engineering for Industry, 112(2): 113-121. [doi:10.1115/1.2899553]

Mansuy, M., Giordano, M., Hernandez, P., 2011. A new calculation method for the worst case tolerance analysis and synthesis in stack-type assemblies. Computer-Aided Design, 43(9):1118-1125. [doi:10.1016/j.cad.2011.04. 010]

Mcadams, D., 2003. Identification and codification of principles for functional tolerance design. Journal of Engineering Design, 14(3):355-375. [doi:10.1080/ 0954482031000091095]

Moroni, G., Petrò, S., 2014. Optimal inspection strategy planning for geometric tolerance verification. Precision Engineering, 38(1):71-81. [doi:10.1016/j.precisioneng. 2013.07.006]

Morse, E.P., Srinivasan, V., Voelcker, H.B., 2012. Size tolerancing revisited: a basic notion and its evolution in standards. 12th CIRP Conference on Computer Aided Tolerancing, Huddesfield, UK.

Nigam, S.D., Turner, J.U., 1995. Review of statistical approaches to tolerance analysis. Computer-Aided Design, 27(1):6-15. [doi:10.1016/0010-4485(95)90748-5]

Parkinson, D., 1982. The application of reliability methods to tolerancing. Journal of Mechanical Design, 104(3):612618. [doi:10.1115/1.3256395]

Qureshi, A.J., Dantan, J.Y., Sabri, V., et al., 2012. A statistical tolerance analysis approach for over-constrained mechanism based on optimization and Monte Carlo simulation. Computer-Aided Design, 44(2):132-142. [doi:10.1016/j.cad.2011.10.004]

Savio, E., Hansen, H.N., de Chiffre, L., 2002. Approaches to the calibration of freeform artefacts on coordinate measuring machines. CIRP Annals-Manufacturing Technology, 51(1):433-436. [doi:10.1016/S0007-8506 (07)61554-6]

Sprauel, J., Linares, J., Bachmann, J., et al., 2003. Uncertainties in CMM measurements, control of ISO specifications. CIRP Annals-Manufacturing Technology, 52(1):423-426. [doi:10.1016/S0007-8506(07)60616-7]

Taguchi, G., 1978. Performance analysis design. The International Journal of Production Research, 16(6): 521-530. [doi:10.1080/00207547808930043]

Walter, M., Sprügel, T., Wartzack, S., 2013. Tolerance analysis of systems in motion taking into account interactions between deviations. Proceedings of the Institution of Mechanical Engineers, Part B: Journal of Engineering Manufacture, 0954405412473719. [doi:10. 1177/0954405412473719]

Wu, F., Dantan, J.Y., Etienne, A., et al., 2009. Improved algorithm for tolerance allocation based on Monte Carlo simulation and discrete optimization. Computers \& Industrial Engineering, 56(4):1402-1413. [doi:10.1016/j. cie.2008.08.001]

Yang, J.X., Xu, X.S., Cao, Y.L., et al., 2010. Functional tolerance specification design based on assembly positioning. Journal of Mechanical Engineering, 46(2): 1-8 (in Chinese). [doi:10.3901/JME.2010.02.001

Yang, J.X., Wang, J.Y., Wu, Z.Q., et al., 2013. Statistical tolerancing based on variation of point-set. Procedia CIRP, 10:9-16. [doi:10.1016/j.procir.2013.08.006]

\section{中文概要}

题 目: 计算机辅助公差设计中的关键问题研究

概 要: 作为机械产品设计和制造过程中的一项重要内 容, 计算机辅助公差设计 (CAT) 是 $\mathrm{CAD} / \mathrm{CAPP} / \mathrm{CAM}$ 集成的关键技术，是国内外先 进制造技术发展中亟需解决的问题。计算机辅助 公差设计覆盖面非常广泛, 涵盖公差规范和标准 化、设计/制造工艺/产品生命周期管理中的公差 设计、检测与测量以及功能公差设计。本文首先 简要分析这些热点问题的研究进展情况, 其次介 绍本专辑收集的第 13 届国际生产工程科学院计 算机辅助公差设计会议中的最新研究成果, 分析 该领域的最新研究进展, 希望能帮助读者了解相 关研究工作并促进研究人员开展讨论, 进一步实 现计算机辅助公差设计中的关键技术的突破, 促 进 $\mathrm{CAD} / \mathrm{CAPP} / \mathrm{CAM}$ 的集成。

关键词: 计算机辅助公差设计; 公差规范与标准; 公差设 计; 检测与测量; 功能公差设计 


\section{Introducing Guest Editors-in-Chief:}

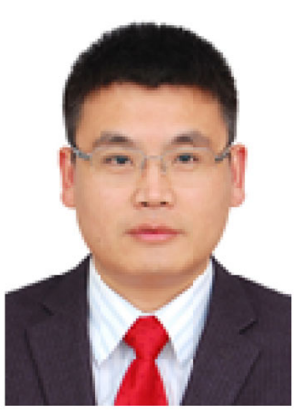

Dr. Yan-long CAO

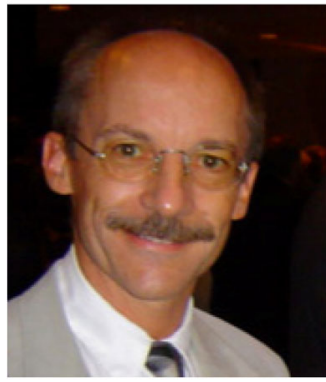

Dr. Luc MATHIEU

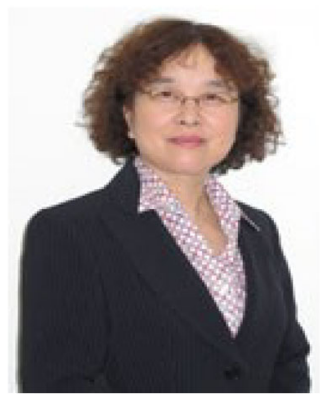

Dr. Jane JIANG
Dr. Yan-long CAO received his $\mathrm{PhD}$ degree in Mechanical Engineering in 2003 from Zhejiang University, China. Dr. CAO was a postdoctoral fellow from 2003 to 2005 at Zhejiang University, and a visiting scholar (2007-2009) at the University of Huddersfield, UK. In 2005, he joined Zhejiang University, where he is an active faculty member in teaching and research and was promoted to associate professor and full professor in 2005 and 2012, respectively. Dr. CAO currently is a professor of mechanical engineering at the School of Mechanical Engineering, Zhejiang University, leading his Tolerancing and Measurement Group with research interest in computer aided tolerancing and precision measurement. His research was supported by more than ten research grants, including the National Natural Science Foundation of China (NSFC). As an author and co-author, he has published more than 60 peer-reviewed journal papers and 10 conference papers, and has had about twenty patents in China approved.

Currently, Dr. CAO serves as the member of National Gear Standardization Technical Committees of China (TC52) and Member of National GPS Standardization Technical Committees of China (SAC/TC240).

Dr. Luc MATHIEU is a full professor at the Department of Mechanical Engineering in Cachan Institute of Technology in France. He received the PhD degree in Manufacturing and Automation in 1986 from Ecole Centrale de Paris and the "Habilitation à Diriger les Recherches" degree in 2007 from Grenoble University, France. His research interests include digital production engineering, geometry \& uncertainty for production engineering, integrated design \& production. He has authored, co-authored, or edited more than 100 scientific articles including book chapters and supervised $25 \mathrm{MSc}$ candidates and co-supervised/supervised 10 $\mathrm{PhD}$ and Postdoc candidates.

Dr. Luc MATHIEU is a fellow member of CIRP since 2003, the prestigious International Academy for Production Engineering. He was secretary, vice-Chairman and Chairman of CIRP STC Dictionary. He is a very active co-chair and chair of the CIRP Computer Aided Tolerancing Seminar and Conference since the creation, held in Israel (1989), the USA (1991; 2003; 2005), France (1993), Japan (1995), Canada (1997), the Netherlands (1999), France (2001), Germany (2007), France (2009), and the UK (2012).

Dr. Jane JIANG holds the chair of precision metrology at the Centre for Precision Technologies, University of Huddersfield, UK. She has a PhD in Surface Measurement Science and a DSc in Precision Engineering. She is a principle member of the ISO TC/213 committee "Dimensional Geometrical Produces Specification and Verification" and the BSI TW/4 committee "Engineering Drawing, Metrology, Precision Measurement", and a UK Government Measurement Advisory Committee Member. Dr. JIANG is a Fellow of the Institute of Engineering Technology (IET), and a Fellow of the Royal Society of Arts, Manufactures and Commerce (RSA). She was awarded Royal Society Wolfson Merit Award in 2006. 